\title{
Rational Quadratic Bézier Spirals
}

(Pilinan Kuadratik Nisbah Bézier)

\author{
AZHAR AHMAD* \& R.U. GOBITHAASAN
}

\begin{abstract}
A quadratic Bézier representation withholds a curve segment with free from loops, cusps and inflection points. Furthermore, this rational form provides extra freedom to generate visually pleasing curves due to the existence of weights. In this paper, we propose sufficient conditions for rational quadratic Bézier curves to possess monotonic increasing/decreasing curvatures by means of monotone curvature tests which are based on the derivative of curvature functions. We have derived a simple interval of the middle weight that assures the construction of a family of rational quadratic Bézier curves to be planar spirals, which is characterized by the turning angle, end curvatures and the chords of control polygon. The proposed formulation can be used by CAD systems for aesthetic product design, highway/railway design and robot trajectory design avoiding unwanted curvature oscillations.
\end{abstract}

Keywords: Bézier curves; curvature; monotonicity; rational quadratics; spirals

\section{ABSTRAK}

Suatu perwakilan kuadratik Bézier akan memastikan satu segmen lengkung yang bebas daripada gelung, punding serta titik lengkungbalas. Selain itu, bentuk nisbahnya pula memberikan lebih kebebasan bagi menjana lengkungan yang menyenangkan dengan sebab kewujudan pemberat. Dalam makalah ini, kami mencadangkan semua syarat yang cukup untuk suatu lengkung nisbah kuadratik Bézier untuk memiliki kelengkungan yang monoton secara meningkat/menurun melalui ujian kelengkungan monoton, yang berasaskan pembezaan fungsi kelengkungan. Kami menafsirkan satu selang mudah merujuk kepada pemberat tengah yang menjamin pembinaan satu keluarga lengkung nisbah kuadratik Bézier sebagai suatu pilinan satah. Ia dicirikan oleh sudut putaran, kelengkungan hujung dan sisi-sisi poligon kawalan. Rumus yang dicadangkan ini boleh diguna pakai pada sistem CAD untuk reka bentuk produk estetik, reka bentuk lebuhrayal landasan keretapi dan reka bentuk trajektori robot yang dapat menghindar ayunan yang tidak diingini pada kelengkungan.

Kata kunci: Kelengkungan; kemonotanan; kuadratik nisbah; lengkung Bezier; pilinan

\section{INTRODUCTION}

Spirals have several advantages of containing neither inflection points, singularities and nor curvature extrema. Such curves are widely used in various CAD/CAM and Computer Graphics applications. Spirals are generally suitable to overcome the abrupt change in curvature, as a result spiral arcs are considered to be an important element to generate a shape preserving interpolation which gives 'visually pleasing' curves of monotone curvature. For some application of CAD/CAM it is important to maintain strictly monotone curvature along a curve segment. This good geometry property allows the curve segment contains no extraneous 'bumps' or 'wiggles', which makes it more readily acceptable to scientists and engineers. Hence, the continuity of curvature profile is an essential indicator for the aesthetic value of an arbitrary shape. Many considerable literatures are available for the stated matter, in Farin (1989), Higashi et al. (1988) and Yoshida et al. (2007).

A simple representation of a spiral segment which preserves the monotonicity of curvature function is by means of parametric polynomial representation. The
Bezier-Bernstein representation is one of most common types of polynomial parametric curve. In general, Bézier curves of degree higher than two provides a greater range of shapes in which their flexibility makes it suitable for the composition of blending curves. However, a spiral construction by using quadratic form has an advantage of having a parametric representation without any cusps, loops and inflection points. Therefore, it will be a great benefit for designers to have optimal control and at the same time reducing the computation power and time significantly.

Rational quadratic Bézier curves provide extra flexibility as compared to the original integral quadratic form and have been widely used in CAD/CAM and Solid Modeling (Farin et al. 1987; Lee 1987; Pavlidis 1983). For example, they are an important design tool in the aircraft industry (Kulfan et al. 2006); they are also used in areas such as font design (Farin 2014; Rusdi \& Yahya 2015). Quadratic Bézier curves form the basis for the TrueType font technology, while higher order Bézier curves lie at the heart of PostScript and a number of draw programs like Adobe Illustrator (Lyche \& Mørken 2008). They are also 
known as conic splines since it can represent conic curve analytically. Conic sections cannot be exactly represented by nonrational polynomials (Hu 2014). Rational quadratic Bézier curves with additional of weights at control points offer an excellent and preferred method to represent spirals. There is a considerable number of studies in the literature which related to condition of the monotonicity of curvature function. Sapidis and Frey (1992) describes a geometric condition that indicates when a quadratic Bézier curve segment has monotone curvature. Ahn and Kim (1998) used symmetry of conics to obtain necessary and sufficient conditions for the curvature of the quadratic rational Bézier curve to be monotonic, where it has unique local minimum, a local maximum and both extrema. Suenaga and Sakai (1999) proposed necessary and sufficient conditions for the rational quadratic Bézier curve to be a spiral or have local extrema by means of differential and Descartes' rule of signs. Furthermore, Frey and Field (2000) analysed the curvature distributions of segments of conics and the geometric interpretation of control points of quadratic rational Bézier curve to be strictly monotone is shown in detail. In a later paper, Li et al. (2006) presented the necessary and sufficient conditions of monotone curvature for the uniform rational quadratic B-spline segment and compared it to the curvature condition of rational quadratic Bézier curve.

In this paper, we propose a simple derivation of sufficient conditions for a quadratic rational Bézier curve to be a spiral. It is found that if the turning angle of the curve is less than or equal to $90^{\circ}$, then there exist a real number representing the weights of quadratic rational Bézier curve to ensure strict monotonicity of the curvature distribution. A family of spiral is proposed for direct construction of single transition segment or a piecewise curve for interpolation or fitting given data points. We applied the monotone curvature test which indicated a clear constraint of values of the weights. We have also derived the range of the weights which results with local extrema in curvature distribution.

The paper is organized as follows; next section describes some basic properties of general rational Bézier form and its' curvature which is used extensively throughout this paper. After that, we introduces rational quadratic Bézier curve in a standard form and its properties. We discuss the necessary and sufficient conditions for the quadratic rational Bézier curve to be a spiral subsequently. In this section, four essential theorems are proposed which depicts our results. Finally, numerical examples are given in final section before final conclusion is made.

\section{RATIONAL BÉZIER FORM AND CURVATURE}

The general $n$-th degree of rational Bézier curve has the form of,

$$
Z(t)=\frac{\sum_{i=0}^{n} B_{i}^{n}(t) w_{i} V_{i}}{\sum_{i=0}^{n} B_{i}^{n}(t) w_{i}}, 0 \leq t \leq 1,
$$

where $V_{i}$ is the control points; is the Bernstein polynomial; and $t$ is a local parameter (Farin 2014). Thus $w_{i}$ represents the weight, which in practice $w_{i}>0$ ensures that weighted basis functions are positive and non-zero; $\sum_{i=0}^{n} B_{i}^{n}(t) w_{i}>0$ and therefore $z(t)$ is well defined. The rational form contains the non-rational or better known as an integral form when all weights are equal to 1 . The curvature is one of the most important shape interrogation tool of curves and surfaces which was established from differential geometry of $\mathbb{R}^{j}, j=2,3$. It is widely used in determining the quality of the approximated curves or surfaces and to construct fair interpolant curves and surfaces. In particular, it is used as a measure of how much a curve or surface 'bends' and to describe the shape of a curve or surface in the vicinity of a point on that curve or surface. For a planar parametric curve, the signed curvature of $Z(t)$ is defined as stated in (3). The curvature of a curve is the reciprocal of radius of osculating circle and the curvature is zero for a straight line. The curvature can be computed from the first and second derivatives of rational Bézier curve.

$$
\kappa(t)=\frac{\left|Z^{\prime}(t) \wedge Z^{\prime \prime}(t)\right|}{\|\left. Z^{\prime}(t)\right|^{\beta}}
$$

The signed curvature is defined as positive when the curve turns left and negative when it turns right as we travel along the curve.

$$
\kappa(t)=\frac{Z^{\prime}(t) \wedge Z^{\prime \prime}(t)}{\left\|Z^{\prime}(t)\right\|^{3}}
$$

The curvature at an end point of a general rational Bézier curve is given as in Sederberg (2012),

$$
\kappa(0)=\frac{w_{0} w_{2}}{w_{1}^{2}} \frac{n-1}{n} \frac{h}{\ell^{2}},
$$

where $\ell=|| V_{1}-V_{0} \mid$ and $h$ is the perpendicular distance from $V_{2}$ to the first leg of control polygon $V_{0} V_{1} V_{2} \ldots V_{n}$. We need to find the first derivative of $\kappa(t)$ to analyse the monotonicity of the curvature:

$$
\kappa^{\prime}(t)=\frac{\phi(t)}{\left\|Z^{\prime}(t)\right\|^{5}}
$$

where

$$
\begin{aligned}
\phi(t)= & \frac{d\left(Z^{\prime}(t) \wedge Z^{\prime \prime}(t)\right)}{d t}\left(Z^{\prime}(t) \cdot Z^{\prime}(t)\right) \\
& -\frac{3}{2}\left(Z^{\prime}(t) \wedge Z^{\prime \prime}(t)\right) \frac{d\left(Z^{\prime}(t) \cdot Z^{\prime}(t)\right)}{d t}
\end{aligned}
$$

The function $\phi(t)$ is known as monotone curvature test. The curvature of a curve is monotonic if $\phi(t) \neq 0$ as $t$ $\in[0,1]$. 


\section{RATIONAL QUADRATIC BÉZIER CURVE}

The standard form of a rational quadratic Bézier curve with $n=2$, is given as,

$$
Z(t)=\frac{(1-t)^{2} V_{0}+2(1-t) t w_{1} V_{1}+t^{2} V_{2}}{(1-t)^{2}+2(1-t) t w_{1}+t^{2}}, 0 \leq t \leq 1,
$$

where $V_{i}, i=0,1,2$ are the control points of the rational quadratic Bézier curve, $\mathrm{w}_{0}=w_{2}=1$ and $w_{1}$ is the middle weight. It is well known that any rational quadratic Bézier curve is a conic segment. The curve is a segment of parabola when the weight $w_{1}=1$, and the curve is a segment of ellipse or a segment of hyperbola when $w_{i}$ is less than or larger than 1 , respectively. If the control polygon $V_{0} V_{1} V_{2}$ forms an isosceles triangle, if $\theta$ is turning angle and $w_{1}=\cos (\theta / 2)$, then the quadratic rational Bézier curve is a circular arc (Lee 1987). We can easy prove these propositions by finding the intrinsic equation from the $x$ and $y$ component based on (6).

\section{MONOTONICITY}

Generally, the method to derive the condition for the existence of curvature extreme is by using monotone curvature test. The main idea of this method is by imposing some restrictions that allow the use of a single rational quadratic curve as a spiral segment. The following describe the conditions in detail.

Firstly, let us assign in general that the length between control points are $a=\| V_{1}-V_{0}||$ and $b=\left|V_{2}-V_{1}\right| \mid$. For simplicity, let $m=b / a$ and the turning angle where $\theta=\cos ^{-1}\left(\left(V_{1}-V_{0}\right) \cdot\left(V_{2}-V_{1}\right) /\left\|V_{1}-V_{0}\left|\| V_{2}-V_{1}\right| \mid\right)\right.$. The curvature at end points can be obtained directly from (4) as follows:

$$
\kappa(0)=\frac{m \sin \theta}{2 w_{1}^{2} a} \text { and } \kappa(1)=\frac{\sin \theta}{2 w_{1}^{2} m^{2} a} \text {. }
$$

Hence, we get $m^{3}=\kappa(0) / \kappa(1)$. Second, since we interested in finding the interval of $w_{1}$, without any loss of generality, we can assign the first control point as $V_{0}$ $=(0,0)$ and the unit vector tangent at this control point is . Hence, $V_{1}=V_{0}+a T_{0}, V_{2}=V_{1}+b T_{1}$ and $T_{1}=(\cos \theta$, $\sin \theta)$. The sign of the curvature is positive because the curve segment bends to the left of $T_{0}$ with respect to $t$. Substituting $V_{i},(i=0,1,2)$ and $T_{i},(i=0,1)$ into (7), we represent $Z(t)=(x(t), y(t))$ as follows,

$$
\begin{aligned}
& x(t)=\frac{a t^{2}(1+m \cos \theta)+2 a(1-t) t w_{1}}{(1-t)^{2}+t^{2}+2(1-t) t w_{1}} \\
& y(t)=\frac{a m t^{2} \sin \theta}{(1-t)^{2}+t^{2}+2(1-t) t w_{1}}
\end{aligned}
$$

From the first and the second derivative of $Z(t)$, we obtain the cross products as,

$$
Z^{\prime}(t) \wedge Z^{\prime \prime}(t)=-\frac{4 a^{2} m w_{1} \sin \theta}{\left(-1+2 t-2 t^{2}-2 t w_{1}+2 t^{2} w_{1}\right)^{3}} .
$$

and the dot products

$$
\begin{gathered}
4 a^{2}\left(m^{2} t^{2} \sin ^{2} \theta\left(1-t+t w_{1}\right)^{2}+((-1+t)\right. \\
Z^{\prime}(t) \cdot Z^{\prime}(t)=\frac{\left.\left.t(1+m \cos \theta)-\left((-1+t)^{2}+m t^{2} \cos \theta\right) w_{1}\right)^{2}\right)}{\left(1-2 t+2 t^{2}-2(-1+t) t w_{1}\right)^{4}},
\end{gathered}
$$

where $\left\|Z^{\prime}(t)\right\|=\sqrt{Z^{\prime}(t)^{\bullet} Z^{\prime}(t)}$. Finally, we obtain the curvature function after substituting (11) and (12) into (3). By using (5) and (6) we further derive the first derivative of curvature,

$$
\begin{aligned}
\kappa^{\prime}(t)= & \frac{3 w_{1} \sin \theta\left(-1+2 t-2 t^{2}-2 t w_{1}+2 t^{2} w_{1}\right)^{2} m \Upsilon}{2 a\left(m^{2} t^{2} \sin ^{2} \theta\left(1-t+t w_{1}\right)^{2}+\right.} \\
& \left.\left((-1+t) t(1+m \cos \theta)-\left((-1+t)^{2}+m t^{2} \cos \theta\right) w_{1}\right)^{2}\right)^{5 / 2}
\end{aligned}
$$

where $\phi(t)=3 w_{1} \sin \theta\left(-1+2 t-2 t^{2}-2 t w_{1}+2 t^{2} w^{1}\right)^{2} m \Upsilon$ is a monotone curve test function. Clearly, the sign of (13) is depends only on a polynomial of degree 4 with respect to $t$, which we denoted as $\Upsilon=\Upsilon(t)$, due to the fact that $3 w_{1}$ $\sin \theta\left(-1+2 t-2 t^{2}-2 t w_{i}+2 t^{2} w_{1}\right)^{2} m$ and the denominator are positive. In order to investigate the monotonicity of the curvature, we re-write $Y$ in the form of Bernstein polynomial as,

$$
\Upsilon=\sum_{k=0}^{4}\left(\begin{array}{c}
4 \\
k
\end{array}\right)(1-t)^{4-k} t^{k} a_{k} .
$$

where the coefficient of the basis functions are as follows,

$$
\begin{aligned}
& a_{0}=w_{1}\left(-1-m \cos \theta+2 w_{1}^{2}\right) \\
& a_{1}=\frac{1}{4}\left(-1-m^{2}-2 m \cos \theta+4 w_{1}^{2}\right) \\
& a_{2}=-\frac{1}{2}\left(-1+m^{2}\right) w_{1} \\
& a_{3}=\frac{1}{4}\left(1+m^{2}+2 m \cos \theta-4 m^{2} w_{1}^{2}\right) \\
& a_{4}=m w_{1}\left(m+\cos \theta-2 m w_{1}^{2}\right)
\end{aligned}
$$

The Bernstein basis functions are commonly used bases in space polynomial and preserve many useful properties. For convenience, we rewrite (15) in a factor form in the term of $w_{1}$ as shown next. 


$$
\begin{aligned}
& a_{0}=2 w_{1}\left(w_{1}+\frac{\sqrt{1+m \cos \theta}}{\sqrt{2}}\right)\left(w_{1}-\frac{\sqrt{1+m \cos \theta}}{\sqrt{2}}\right) \\
& a_{1}=\left(w_{1}+\frac{1}{2} \sqrt{1+m^{2}+2 m \cos \theta}\right)\left(w_{1}-\frac{1}{2} \sqrt{1+m^{2}+2 m \cos \theta}\right) \\
& a_{2}=-\frac{1}{2}\left(-1+m^{2}\right) w_{1} \\
& a_{3}=-m^{2}\left(w_{1}+\frac{1}{2 m} \sqrt{1+m^{2}+2 m \cos \theta}\right) \\
& \left(w_{1}-\frac{1}{2 m} \sqrt{1+m^{2}+2 m \cos \theta}\right) \\
& a_{4}=-2 m^{2} w_{1}\left(w_{1}+\frac{\sqrt{m+\cos \theta}}{\sqrt{2} \sqrt{m}}\right)\left(w_{1}-\frac{\sqrt{m+\cos \theta}}{\sqrt{2} \sqrt{m}}\right) .
\end{aligned}
$$

The following theorems define sufficient conditions for a single rational quadratic Bézier curve to possess monotonic curvature on $t \in[0,1]$. For simplicity, let $w_{L} \equiv \frac{\sqrt{1+m \cos \theta}}{\sqrt{2}}$ and $w_{U} \equiv \frac{\sqrt{m+\cos \theta}}{\sqrt{2} \sqrt{m}}$.

\section{THEOREM 1}

If $w_{L}<w_{1}<w_{U}$ and $0<m<1$, then the curvature of the rational quadratic Bézier curve as stated in (7) is monotonically increasing. And if $w_{U}<w_{L}$ and $m>1$, then the curvature of the rational quadratic Bézier curve as stated (7) is monotonically decreasing.

\section{PROOF 1}

It is evident from (8) that when $0<m<1$ we get $\kappa(0)<$ $\kappa(1)$. For $\kappa^{\prime}(t)>0$ the sign of $\Upsilon$ should be positive, so it will occur if $a_{k}>0,(k=0,1,2,3,4)$. First, let us write $D_{k}$, $(k=0,1,2,3,4)$ as the set of $w_{1}$ for $a_{k}>0$. So the following $D_{k}$ that corresponds to $a_{k}$ are;

$$
\begin{aligned}
& D_{0}=\left\{w_{1}: w_{1}>\frac{\sqrt{1+m \cos \theta}}{\sqrt{2}}\right\} \\
& D_{1}=\left\{w_{1}: w_{1}>\frac{1}{2} \sqrt{1+m^{2}+2 m \cos \theta}\right\} \\
& D_{2}=\left\{w_{1}: w_{1}>0\right\} \\
& D_{3}=\left\{w_{1}: 0<w_{1}<\frac{1}{2 m} \sqrt{1+m^{2}+2 m \cos \theta}\right\} \\
& D_{4}=\left\{w_{1}: 0<w_{1}<\frac{\sqrt{m+\cos \theta}}{\sqrt{2} \sqrt{m}}\right\}
\end{aligned}
$$

To satisfy all $a_{k}>0$, we need to obtain an interval of $w_{1}$ from this operation, $\bigcap_{k=0}^{4} D_{k}$. We begin with

$$
\begin{aligned}
D_{0} \cap D_{1}= & \left\{w_{1}: w_{1}>\frac{\sqrt{2} m \sqrt{1+m \cos \theta}}{2 m}\right\} \\
& \cap\left\{w_{1}: w_{1}>\frac{\sqrt{2} m \sqrt{1+m \cos \theta+\left(m^{2}-1\right) / 2}}{2 m}\right\}=D_{0}
\end{aligned}
$$

since $-1 / 2<\left(m^{2}-1\right) / 2<0$. Furthermore

$$
\begin{aligned}
D_{3} \cap D_{4}= & \left\{w_{1}: 0<w_{1}<\frac{\sqrt{2} \sqrt{m} \sqrt{\left(1-m^{2}\right) / 2 m+(m+\cos \theta)}}{2 m}\right\} \\
& \cap\left\{w_{1}: 0<w_{1}<\frac{\sqrt{2} \sqrt{m} \sqrt{m+\cos \theta}}{2 m}\right\}=D_{4},
\end{aligned}
$$

where $\left(1-m^{2}\right) / 2 m>0$. Therefore,

$$
\begin{aligned}
D_{0} \cap D_{4}= & \left\{w_{1}: w_{1}>\frac{\sqrt{2} m \sqrt{1+m \cos \theta}}{2 m}\right\} \\
& \cap\left\{w_{1}: 0<w_{1}<\frac{\sqrt{2} m \sqrt{1+(\cos \theta) / m}}{2 m}\right\} \\
= & \left\{w_{1}: \frac{\sqrt{2} m \sqrt{1+m \cos \theta}}{2 m}<w_{1}<\frac{\sqrt{2} m \sqrt{1+(\cos \theta) / m}}{2 m}\right\} \\
= & \left\{w_{1}: \frac{\sqrt{1+m \cos \theta}}{\sqrt{2}}<w_{1}<\frac{\sqrt{m+\cos \theta}}{\sqrt{2} \sqrt{m}}\right\} .
\end{aligned}
$$

Since $1<1+m \cos \theta<1+m$ and $1<1+\frac{\cos \theta}{m}<1+\frac{1}{m}$, and with $w_{1}>0$ from $D_{2}$, the result is

$$
\bigcap_{k=0}^{4} D_{k}=\left\{w_{1}: w_{L}<w_{1}<w_{U}\right\}
$$

This concludes that the curvature of $Z(t)$ is monotone increase as $\kappa^{\prime}(t)>0$.

Analogous to previous proof, for $m>1$ we get $\kappa(0)$ $>\kappa(1)$. Thus, $\kappa^{\prime}(t)<0$ which means $\Upsilon<0$. Therefore, we need for $a_{k}<0$. First, we write the following $D_{k}$ that corresponds to $a_{k}<0$ as;

$$
\begin{aligned}
& D_{0}=\left\{w_{1}: 0<w_{1}<\frac{\sqrt{1+m \cos \theta}}{\sqrt{2}}\right\} \\
& D_{1}=\left\{w_{1}: 0<w_{1}<\frac{1}{2} \sqrt{1+m^{2}+2 m \cos \theta}\right\} \\
& D_{2}=\left\{w_{1}: w_{1}>0\right\}
\end{aligned}
$$




$$
\begin{aligned}
& D_{3}=\left\{w_{1}: w_{1}>\frac{1}{2 m} \sqrt{1+m^{2}+2 m \cos \theta}\right\} \\
& D_{4}=\left\{w_{1}: w_{1}>\frac{\sqrt{m+\cos \theta}}{\sqrt{2} \sqrt{m}}\right\} .
\end{aligned}
$$

To fulfil all $a_{k}<0$ we require to obtain an interval of $w_{1}$ that satisfies $\bigcap_{k=0}^{4} D_{k}$. So,

$$
\begin{aligned}
D_{0} \cap D_{1}= & \left\{w_{1}: 0<w_{1}<\frac{\sqrt{2} m \sqrt{1+m \cos \theta}}{2 m}\right\} \\
& \cap\left\{w_{1}: 0<w_{1}<\frac{\sqrt{2} m \sqrt{1+m \cos \theta+\left(m^{2}-1\right) / 2}}{2 m}\right\}=D_{0},
\end{aligned}
$$

since $\left(m^{2}-1\right) / 2>0$. And

$$
\begin{aligned}
D_{3} \cap D_{4}= & \left\{w_{1}: w_{1}>\frac{\sqrt{2} \sqrt{m} \sqrt{\left(1-m^{2}\right) / 2 m+(m+\cos \theta)}}{2 m}\right\} \\
& \cap\left\{w_{1}: w_{1}>\frac{\sqrt{2} \sqrt{m} \sqrt{m+\cos \theta}}{2 m}\right\}=D_{4},
\end{aligned}
$$

where $\left(1-m^{2}\right) / 2 m<0$. Thus

$$
\begin{aligned}
D_{0} \cap D_{4} & =\left\{w_{1}: 0<w_{1}<\frac{\sqrt{2} m \sqrt{1+m \cos \theta}}{2 m}\right\} \\
& \cap\left\{w_{1}: w_{1}>\frac{\sqrt{2} m \sqrt{1+(\cos \theta) / m}}{2 m}\right\} \\
= & \left\{w_{1}: \frac{\sqrt{2} m \sqrt{1+(\cos \theta) / m}}{2 m}<w_{1}<\frac{\sqrt{2} m \sqrt{1+m \cos \theta}}{2 m}\right\} \\
= & \left\{w_{1}: \frac{\sqrt{m+\cos \theta}}{\sqrt{2} \sqrt{m}}<w_{1}<\frac{\sqrt{1+m \cos \theta}}{\sqrt{2}}\right\}
\end{aligned}
$$

since $1<1+m \cos \theta<1+m$ and $1<1+\frac{\cos \theta}{m}<1+\frac{1}{m}$. This results lead to a final conclusion that the curvature of $Z(t)$ is monotonic decreasing when $m>1$ and,

$$
\bigcap_{k=0}^{4} D_{k}=\left\{w_{1}: w_{U}<w_{1}<w_{L}\right\}
$$

From the above theorem, we can derive the constant curvature conditions which result with circular arcs.

\section{REMARK}

If $m=1$ then the curvature of the rational quadratic Bézier curve of the form (7) is constant. Hence $Z(t)$ is a circular arc. By using (8), we obtain $\kappa(1)=\kappa(0)$ as $m=1$, and $w_{1}=\sqrt{1+\cos \theta} / \sqrt{2}=\cos (\theta / 2)$ which implies that $a_{k}=0$, $(k=0,1,2,3,4)$ from $(15)$, indicating $\kappa^{\prime}(t)=0$. This concludes that $\kappa(t)$ is constant.

\section{THEOREM 2}

Suppose that $0<m<1$, if $w_{1}=w_{L}$ or $w_{1}=w_{U}$, then rational quadratic Bézier segment $Z(t)$ have a extremum curvature at $t=0$ or $t=1$, respectively.

\section{PROOF 2}

From (16), if $w_{1}=w_{L}$, then it implies that $a_{0}=0$, and $a_{g}$ $\neq 0,(g=1,2,3,4)$. Since $a_{0}$ is the first coefficient of $\Upsilon$ so $\Upsilon(0)=0$, therefore $\kappa^{\prime}(0)=0$. However, if $w_{1}=w_{U}, a_{4}=0$, and $a_{f} \neq 0,(f=0,1,2,3)$, so we obtain $\Upsilon(1)=0$, therefore $\kappa^{\prime}(1)=0$.

Similarly with above proof, we can obtain an extremum curvature at the endpoints at $t=0$ and $t=1$, if $w_{1}=w_{U}$ or $w_{1}=w_{L}$ respectively, when $m>1$.

\section{THEOREM 3}

Suppose that $0<m<1$, if $0<w_{1}<w_{L}$ then $Z(t)$ has a local minimum curvature. If $w_{1}>w_{U}$ then there exist a local maximum curvature of $Z(t)$.

PROOF 3

Descartes's Rule of sign is used to prove this theorem. First, the extremum of curvature exists when $\kappa^{\prime}(t)=0$ which can obtained from the number of roots when $\Upsilon(t)=0$. By using reparameterization, $\Upsilon(t) \rightarrow \Upsilon(s)$, where $t \in[0,1]$, $s \in[0, \infty)$, with $t=s /(1+s)$, we obtain $\Upsilon(s)=\frac{1}{(1+s)^{4}}\left(a_{0}+\right.$ $\left.4 a_{1} s+6 a_{2} s^{2}+4 a_{3} s^{3}+a_{4} s^{4}\right)$, where $a_{k},(k=0,1,2,3,4)$ are as stated in (16). The sign of the coefficients of $\Upsilon(s)$ can be representing by $\tau(s)=\left(a_{0}+4 a_{1} s+6 a_{2} s^{2}+4 a_{3} s^{3}+a_{4} s^{4}\right)$ since $(1+s)^{4}$ is positive. The sign of the coefficients of $\tau(s)$ is $(-,-,+,+,+)$ or $(-,+,+,+,+)$ after applying $0<w_{1}<$ $\frac{\sqrt{1+m \cos \theta+\left(m^{2}-1\right) / 2}}{\sqrt{2}}$ and $\frac{\sqrt{1+m \cos \theta+\left(m^{2}-1\right) / 2}}{\sqrt{2}}<w_{1}<w_{L}$, respectively. There is only one sign change for the case of $\tau(s)=0$. As a conclusion, there is one positive root in $s \in[0, \infty)$. Since $\Upsilon(0)<0$ and $\Upsilon(1)>0$ in (14), we have one local minimum curvature. The case is the same when we use $w_{1}>w_{U}$. The sequence of coefficient sign is $(+,+$, $+,-,-)$ or $(+,+,+,+,-)$, which implies that there is only one positive root exist in the positive chase for $\tau(\mathrm{s})=0$. Again, since $\Upsilon(0)>0$ and $\Upsilon(1)<0$ in (14), there is one local maximum curvature of $Z(t)$. 


\section{THEOREM 4}

Suppose that $m>1$, for the case of $w_{1}>w_{L}$ then $Z(t)$ has a local maximum curvature extremum. And if $0<w_{1}<w_{U}$ then there exist a local minimum curvature of $Z(t)$.

\section{PROOF 4}

The proposition can be easily derived from the proof of Theorem 3. Clearly, if we substitute $\frac{1}{m}$ onto parameter $m$ in the above theorem which give us $\tau(s)=-\frac{1}{m^{2}}\left(a_{4}+4 a_{3} s\right.$ $\left.+6 a_{2} s^{2}+4 a_{1} s^{3}+a_{0} s^{4}\right)$, we will obtain Theorem 4 .

\section{NUMERICAL EXAMPLES}

We present two examples of spiral drawn with rational quadratic Bézier curve using $G^{1}$ data: and $\alpha=4$. First, we generate monotonic increasing spirals with $m=0.5$. The values of illustrated by dashed line in a shaded region as showed in Figure 1 in which we obtain spirals as shown in Figure 2. Meanwhile, the curvatures of the function as in Figure 3. The second example shows monotonic decreasing spirals with $m=1.5$. The allowable range of middle weight is. The spirals and the curvatures of the function are showed in Figures 4 and 5, respectively.

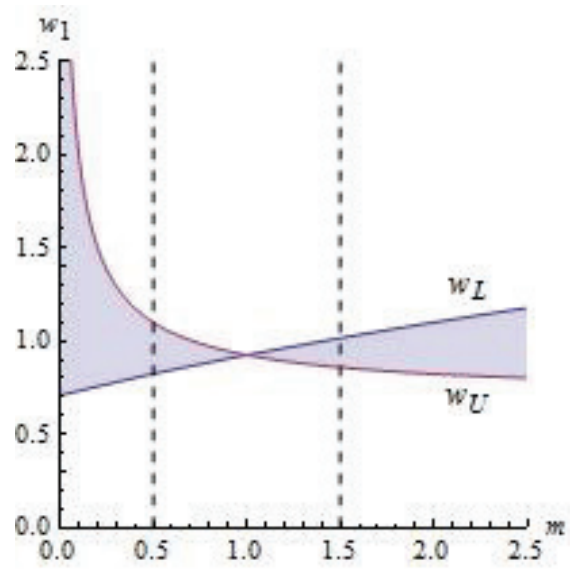

FIGURE 1 . Interval of $w_{1}$ for $m=0.5$ and $m=1.5$ shown by intersection of dashed line and shaded region

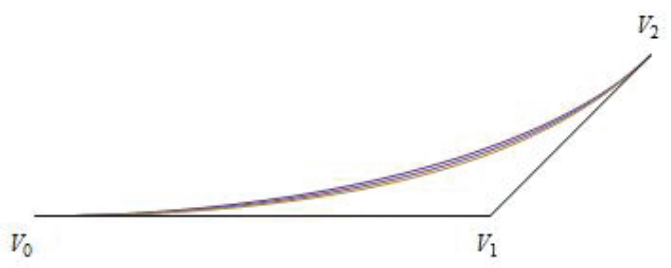

FIGURE 2. Spiral segments with monotonic increasing curvature

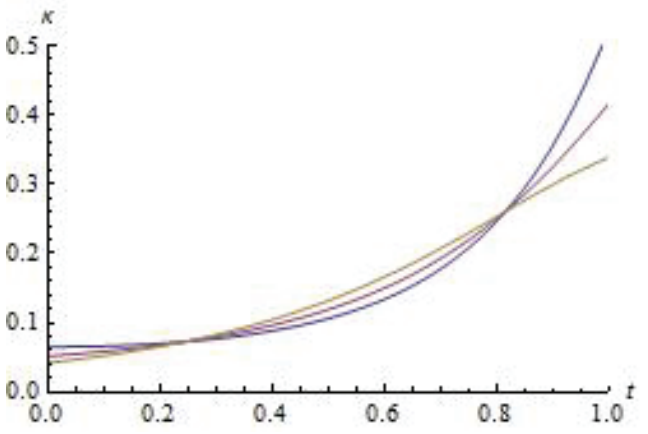

FIGURE 3. Monotone increasing of curvature functions

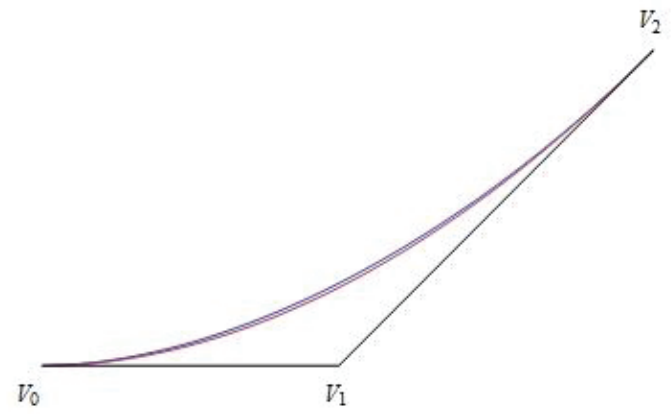

FIGURE 4. Spiral segments with monotonic decreasing curvature

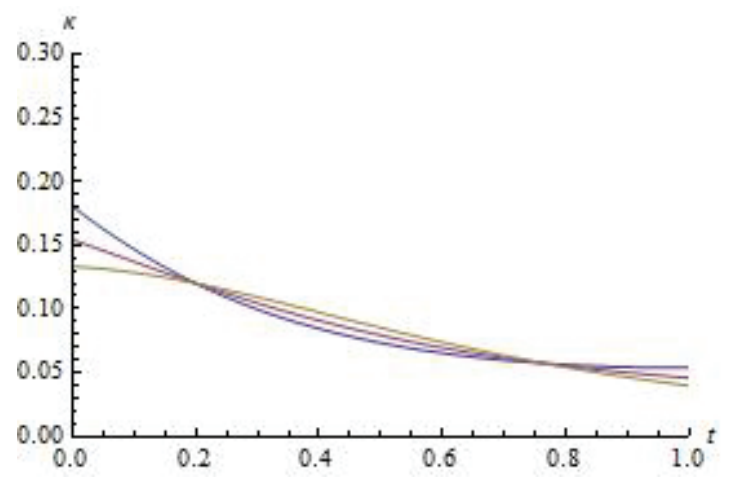

FIGURE 5. Monotone decreasing of curvature functions

\section{CONCLUSION}

In this paper, we proposed sufficient conditions for the curvature of rational quadratic Béziers to be monotonic in $t \in[0,1]$. We also characterized sufficient conditions for the ratio of the lengths of two sides of control lines and middle weight of a quadratic rational Bézier curve to have a unique local minimum, to have a unique local maximum and an extreme curvature point at the end points. The results are obtained from monotonic curvature test which are based on the derivative of curvatures. We have successfully derived an interval of the middle weight to construct a family of rational quadratic spirals of either increasing or decreasing curvatures which can be useful in many applications such as a single transition curve or 
with some simple CAD modification to produce "visually pleasing' monotone spline of rational quadratic curve.

\section{ACKNOWLEDGEMENTS}

This work is financially supported by the Faculty of Science and Mathematics, Universiti Pendidikan Sultan Idris. The authors thank the anonymous referees for their valuable comments and constructive suggestions for improving the readability of this paper.

\section{REFERENCES}

Ahn, Y.J. \& Kim, H.O. 1998. Curvatures of the quadratic rational Bézier curves. Computers \& Mathematics with Applications 36(9): 71-83.

Farin, G. 2014. Curves and Surfaces for Computer-Aided Geometric Design: A Practical Guide. 5th ed. London: Academic Press.

Farin, G. 1989. Curvature continuity and offsets for piecewise conics. ACM Transactions on Graphics (TOG) 8(2): 89-99.

Farin, G., Rein, G., Sapidis, N. \& Worsey,A.J. 1987. Fairing cubic B-spline curves. Computer Aided Geometric Design 4(1-2): 91-103.

Frey, W.H. \& Field, D.A. 2000. Designing Bézier conic segments with monotone curvature. Computer Aided Geometric Design 17(6): 457-483.

Higashi, M., Kaneko, K. \& Hosaka, M. 1988. Generation of highquality curve and surface with smoothly varying curvature. http://dx.doi.org/10.2312/egtp.19881007. pp. 79-92.

Hu, Q. 2014.G1 approximation of conic sections by quartic Bézier curves. Computers \& Mathematics with Applications 68(12): 1882-1891.

Kulfan, B. \& Bussoletti, J. 2006. 'Fundamental' parameteric geometry representations for aircraft component shapes. In 11th AIAA/ISSMO Multidisciplinary Analysis and Optimization Conference. p. 6948.

Lee, E.T. 1987. The rational Bézier representation for conics. In Geometric Modeling: Algorithms and New Ttrends. SIAM: Academic Press. pp. 3-19.

Li, Z., Ma, L., Meek, D., Tan, W., Mao, Z. \& Zhao, M. 2006. Curvature monotony condition for rational quadratic B-spline curves. In International Conference on Computational Science and Its Applications. Springer- Berlin Heidelberg. pp. 1118-1126.
Lyche, T. \& Morken, K. 2008. Spline Methods Draft. Department of Informatics, Center of Mathematics for Applications, University of Oslo, Oslo.

Pavlidis, T. 1983. Curve fitting with conic splines. ACM Transactions on Graphics (TOG) 2(1): 1-31.

Rusdi, N.A. \& Yahya, Z.R. 2015. Pembinaan semula fon arab menggunakan lengkung bézier kuartik. Sains Malaysiana 44(8): 1209-1216.

Sapidis, N.S. \& Frey, W.H. 1992. Controlling the curvature of a quadratic Bézier curve. Computer Aided Geometric Design 9(2): 85-91.

Sederberg, T.W. 2012. Computer aided geometric design. Computer Aided Geometric Design Course Notes. January 10

Suenaga, K. \& Sakai, M. 1999. On curvatures of rational quadratic Bézier segments. Rep.Fac. Sci.32: 15-20.

Yoshida, N. \& Saito, T. 2007. Quasi-aesthetic curves in rational cubic Bézier forms. Computer-Aided Design and Applications 4(1-4): 477-486.

Azhar Ahmad*

Faculty of Science and Mathematics

Universiti Pendidikan Sultan Idris

35900 Tanjung Malim, Perak Darul Ridzuan

Malaysia

R.U. Gobithaasan

School of Informatics \& Applied Mathematics

University Malaysia Terengganu

21030 Kuala Nerus, Terengganu Darul Iman

Malaysia

*Corresponding author; email: azhar.ahmad@ fsmt.upsi.edu.my

Received: 10 January 2018

Accepted: 19 May 2018 